\title{
PERCEPÇÃO DOS RESIDENTES SOBRE O PROCESSO AVALIATIVO E SEUS INSTRUMENTOS NA RESIDÊNCIA MULTIPROFISSIONAL NA ATENÇÃO INTEGRAL EM ORTOPEDIA E TRAUMATOLOGIA
}

\author{
Gabriela Amorim Barreto Alvarenga' \\ Edna Ferreira Coelho Galvão² \\ Silvânia Lins Yukiko Takanashi3
}

\section{RESUMO}

A avaliação deve ser um processo reflexivo sobre a aprendizagem e impulsionadora de sua continuidade, sendo um processo dinâmico e construtivista, permitindo ao avaliador agir da forma mais adequada possível, objetivando a aprendizagem efetiva por parte do educando. As Residências Multiprofissionais em Saúde são programas de pós-graduação de formação prática e teórica, onde o residente é inserido em serviços de saúde por um período de dois anos, com o auxílio e orientação dos preceptores que também possuem a função de avaliadores destes residentes. $O$ instrumento avaliativo em uso atualmente é o REGISTRO DE ATITUDES, uma tabela que lista as competências e habilidades a serem avaliadas no residente. Diante deste cenário pretendeu-se com este estudo, identificar a percepção dos residentes da Residência Multiprofissional sobre o processo avaliativo vigente e seus instrumentos. Os participantes foram ouvidos em uma entrevista estruturada com quatro questões. A análise dos dados seguiu os princípios da Análise de Conteúdo, onde as informações foram tratadas por Categorização e Subcategorização com auxílio do Iramuteq. O estudo demonstrou multiplicidade de saberes sobre o tema, acusando dúvidas e insegurança sobre o processo avaliativo e sua condução no programa de residência resultando em falhas e insatisfação dos envolvidos.

Palavras-chave: Avaliação. Ensino. Residência Multiprofissional.

\footnotetext{
1 Mestrado em Ensino em Saúde na Amazônia. Professora do Curso de Fisioterapia no Instituto Esperança de Ensino Superior, Santarém/PA. E-mail: barretog_a@yahoo.com.br

2 Doutorado em Educação (Universidade Federal Fluminense). Professora do curso de Educação Física - Universidade do Estado do Pará/UEPA, Santarém, PA, Brasil. E-mail: efcgalvao@gmail.com

3 Doutorado em Doenças Tropicais Professora do curso de Fisioterapia da Universidade do Estado do Pará/UEPA, Santarém, PA, Brasil. E-mail: silvaniayukiko@hotmail.com
} 


\title{
EVALUATION PROCESS AND ITS INSTRUMENTS IN MULTIPROFESSIONAL \\ RESIDENCE IN COMPREHENSIVE ATTENTION IN ORTHOPEDICS AND
}

TRAUMATOLOGY - PERCEPTION OF RESIDENTS

\begin{abstract}
The evaluation should be a reflexive process on learning and impelling its continuity, being a dynamic and constructivist process allowing the evaluator to act in the most appropriate way possible, aiming at effective learning on the part of the student. Multiprofessional Residences in Health are postgraduate programs of practical and theoretical training where the resident is inserted in health services for a period of two years, with the help and guidance of the preceptors who also have the function of evaluators of these residents. The evaluation tool currently in use is the REGISTRY OF ATTITUDES, a table that lists the skills and abilities to be evaluated in the resident. In view of this scenario, this study intended to identify the perception of residents of the Multiprofessional Residence about the current evaluative process and its instruments. Participants were heard in a structured interview with four questions. The analysis of the data followed the principles of Content Analysis, where the information was treated by categorization and subcategorization with the help of Iramuteq. The study demonstrated a multiplicity of knowledge about the subject, accusing doubts and insecurity about the evaluation process and its conduction in the residency program resulting in failures and dissatisfaction of those involved.
\end{abstract}

Keywords: Evaluation. Teaching. Nonmedical Internship.

\section{PERCEPCIÓN DE LOS RESIDENTES DEL PROCESO EVALUACIÓN Y SUS INSTRUMENTOS EN LA RESIDENCIA MULTIPROFESIONAL EN LA ATENCIÓN INTEGRAL EN ORTOPEDIA Y TRAUMATOLOGÍA}

\section{RESUMEN}

La evaluación debe ser um proceso reflexivo sobre el aprendizaje e impulsor de su continuidad, siendo um processo dinámico y constructivista permitiendo al evaluador actuar de la forma más adecuada posible, objetivando el aprendizaje efectivo por parte del educando. Las Residencias Multiprofesionales em Salud son programas de postgrado de formación práctica y teórica, donde el residente es insertado em servicios de salud por un período de dos años, con el auxilio y orientación de los preceptores que también poseen la función de evaluadores de estos residentes. El instrumento de evaluación en uso actualmente es el REGISTRO DE ACTITUD, una tabla que enumera las competencias y habilidades a ser evaluadas en el residente. Ante este escenario se pretendió con este estudio identificar la percepción de los residentes de la Residencia Multiprofesional sobre el proceso de evaluación vigente y sus instrumentos. Los participantes fueron oidos en una entrevista estructurada con cuatro preguntas. El análisis de los datos siguió los princípios del Análisis de Contenido, donde la información fue tratada por 
Categorización y Subcategorización con ayuda del Iramuteq. El estúdio demostró multiplicidad de saberes sobre el tema, acusando dudas e inseguridad sobre el processo evaluativo y su conducción en el programa de residencia resultando en fallas e insatisfacción de los involucrados.

Palabras clave: Evaluación. Educación. Residencia Multiprofesional.

\section{INTRODUÇÃO}

A avaliação deve constituir-se em um processo reflexivo sobre a aprendizagem, impulsionando sua continuidade e favorecendo a construção do conhecimento. Neste contexto, o aluno precisa estar consciente de seu próprio processo de construção e de reconstrução, ganhos e perdas, sucesso e fracasso, realizando as adaptações e reorientações necessárias (ALONSO et al., 1992).

As Residências Integrais Multiprofissionais em Saúde (RIMS) são programas de pós-graduação em modalidade lato-sensu e possuem uma carga horária de 5.760 horas de formação prática e teórica. A interdisciplinaridade, por meio de quatorze categorias profissionais da saúde, objetiva uma formação coletiva no mesmo ambiente de trabalho, sem deixar de respeitar a especificidade de saberes inerentes a cada profissão (BRASIL, 2006a).

Na modalidade Residência Multiprofissional, o residente é inserido em serviços do Sistema Único de Saúde (SUS) por um período de dois anos, com - auxílio e orientação de trabalhadores que atuam nesses espaços, os chamados Preceptores (ABIB, 2012). Preceptor é um profissional da saúde que possui duplo papel: assistência nos serviços de saúde acrescida do compromisso de ensinar, orientar, supervisionar e ser modelo para o residente (DIAS; FREITAS, 2014).

A principal função do preceptor é ensinar a clinicar, instruindo formalmente, buscando a competência clínica através do favorecimento da aquisição de habilidades e competências pelos recém-graduados, dentro do ambiente de trabalho em situações clínicas reais. As avaliações formais também fazem parte da atividade da preceptoria (RICER, 1998). E esta é uma atribuição que apresenta grandes desafios, que podem estar 
relacionadas à falta de experiência no ato de avaliar, o conhecimento limitado sobre processo avaliativo, ou ainda, a inconsistência de critérios do preceptor para estabelecer um acompanhamento mais profundo das atividades que o residente desenvolve.

No que tange ao processo de ensino-aprendizagem nos programas de Residência, o Conselho Nacional de Residências Multiprofissionais em Saúde (CNRMS), ao tratar dos Princípios e Diretrizes para os Programas de Residência em Saúde, afirma que o processo de avaliação e monitoramento dos Programas de Residência faça parte de um processo de Educação Permanente em serviço, incluindo avaliação da preceptoria e a punição sobre o residente.

Dentre as Residências Multiprofissionais no Brasil está a Residência Multiprofissional em Saúde, na área de Atenção Integral em Ortopedia e Traumatologia implantada no Hospital Regional do Baixo Amazonas (HRBA) em Santarém, no interior do Estado do Pará, em março de 2013, ofertando vagas para 07 profissões: Terapia Ocupacional, Enfermagem, Psicologia, Fisioterapia, Fonoaudiologia, Serviço Social e Farmácia, através de uma parceria com a Universidade do Estado do Pará (UEPA).

A avaliação é parte integrante do processo de ensino e está flexibilizada de acordo com as particularidades de cada curso. Segundo o projeto pedagógico do programa, a avaliação dos residentes deve se dar de forma processual, através da interação entre educadores e educando, buscando identificar problemas surgidos durante 0 processo ensinoaprendizagem e solucioná-los no decorrer deste processo, sendo o instrumento de coleta de dados para subsidiar a avaliação em campo de prática dos residentes denominado Registro de Atitudes.

Estudos revelam que os programas de Residência Multiprofissional carecem de processos avaliativos, revelando a quase inexistência de avaliação de aprendizagem, ou relatos que esclareçam como estão dispostos os seus processos, demonstrando uma lacuna teórica significativa no quesito de avaliação desses programas (SANTOS, 2010; SOUSA, 2012; SILVA, 2015). 
Diante do exposto, o presente estudo vem investigar: Qual a percepção dos residentes sobre a avaliação de aprendizagem e seus instrumentos utilizados na Residência Multiprofissional, na Atenção Integral em Ortopedia e Traumatologia, revelando os saberes e significados, opiniões e angústias diante do tema.

\section{METODOLOGIA}

A pesquisa segue as normas da Resolução CNS 466/12 e foi aprovada no Comitê de Ética e Pesquisa da Universidade do Estado do Pará - Campus XII, CAAE: 67572317.0.0000.5168, aprovado em 12 de Agosto de 2016. Trata-se de um estudo de abordagem qualitativa, descritivo, utilizando-se de entrevistas semiestruturadas para coletar dos entrevistados residentes percepções e experiências, seus pontos de vistas e significados atribuídos as suas perspectivas sobre o tema.

O presente estudo se utiliza de um conceito atual estabelecido por Turato (2013), associando os métodos qualitativos sócio-antropológicos e clínico-psicológicos na construção de um método mais íntimo e direcionado a indivíduos e ambientes de saúde, definido como Metodologia Clínicoqualitativa. Trata-se de um conjunto de técnicas e procedimentos utilizados para dar significado aos fenômenos humanos a partir de settings de saúde, nesta pesquisa, um programa de pós-graduação em saúde, estabelecendo um método particularizado, baseado no estudo e construção de limites epistemológicos direcionados à área da saúde.

A pesquisa foi desenvolvida no Hospital Regional do Baixo Amazonas (HRBA), com 15 residentes do Programa de Residência Multiprofissional em Saúde, na área de Atenção Integral em Ortopedia e Traumatologia de áreas distintas.

O tratamento dos dados obtidos seguiu as fases sugeridas por Turato (2013) para análise de conteúdo aplicada à pesquisa clínico-qualitativa, e estão descritas a seguir. 
1. Preparação inicial do material: consiste na transcrição das falas dos participantes da pesquisa, que estão em arquivos de áudio, para arquivos de texto no computador (preparação do corpus de análise).

2. Pré-análise: consiste na leitura flutuante e leitura exaustiva do material, a fim de extrair o que está implícito nas falas.

3. Categorização e Subcategorização: nessa fase é realizado agrupamento das falas por afinidade de temas, gerando temas amplos, denominadas categorias que podem derivar outros temas, denominadas subcategorias.

4. Apresentação dos resultados: trata-se da apresentação dos resultados de forma descritiva, na qual as falas dos participantes da pesquisa são colocadas para exemplificar o significado extraído.

Na fase de Categorização e Subcategorização foram seguidos dois princípios básicos, o da repetição, onde foram agrupadas as falas que mais se repetem no discurso dos entrevistados, além do critério da Relevância, que é a separação de segmentos de texto que não têm tanta repetição nos discursos, mas que são importantes para reafirmar ou refutar ideias extraídas dos textos (TURATO, 2013). Nesta fase da pesquisa, recorreu-se ao auxílio do software Iramuteq, ferramenta amplamente utilizada em pesquisas desta natureza metodológica, que ao analisar o corpus procede a uma estatística textual e, através dos princípios de repetição e relevância, faz a classificação de categoria e subcategorias organizando-as graficamente sob a forma de dendograma, identificado como Classificação Hierárquica Descendente (CHD).

\section{RESULTADOS E DISCUSSÃO}

A partir da análise do corpus de cada pergunta, o Iramuteq gerou uma imagem representativa, o dendograma, explicitando as classes de segmentos de textos. O gráfico contém também a porcentagem da frequência de palavras nos segmentos de textos analisados, bem como, o $x^{2}$ (qui-quadrado) exprimindo a associação da palavra com a classe gerada. Quanto maior o x², mais forte foi esta associação. 
Esclarecemos também que todas as análises tiveram um índice de aproveitamento acima $70 \%$ dos segmentos de textos. Para a análise deste corpus, em todas as perguntas, as variáveis padrão do uso do Iramuteq foram mantidas.

Com relação à pergunta 01 do roteiro de entrevista - "Você conhece os métodos/instrumentos utilizados no processo avaliativo da Residência Multiprofissional?", chegou-se as representações abaixo:

GRÁFICO 1 - Gráfico do conteúdo analisado pelo corpus "métodos e instrumentos avaliativos utilizados no programa de residência multiprofissional"

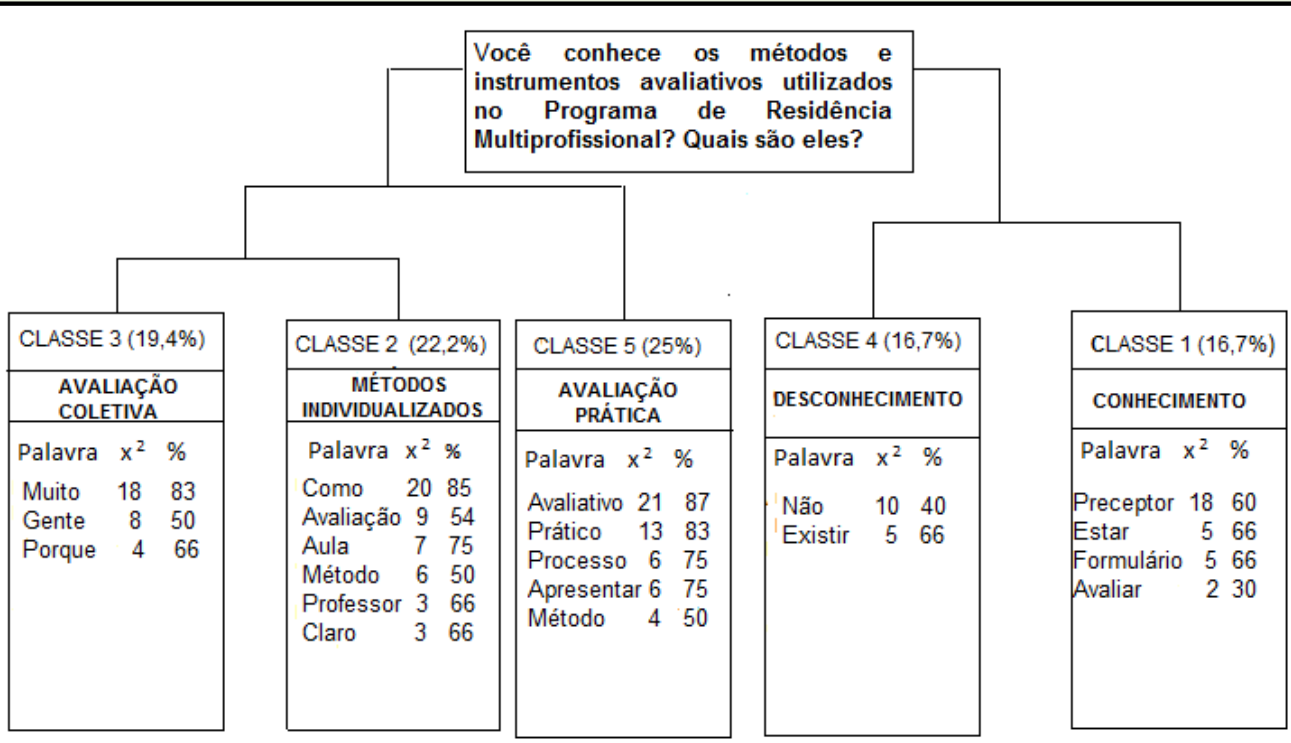

Fonte: Dados do autor (2017).

$\mathrm{Na}$ análise deste corpus, os residentes apresentam discursos em dois sub-corpus. A partição com porcentagem de $16,7 \%$ dos segmentos de textos analisados, refere-se ao CONHECIMENTO dos métodos avaliativos, e que este consiste em uma espécie de formulário que é entregue ao preceptor, o responsável pela avaliação. As falas a seguir ilustram a percepção de existência do instrumento que é utilizado. 
"Os preceptores não têm uma visão de avaliar quando pegam esse formulário" (E8)

"[...] na prática nós temos um formulário que o preceptor vê pontualidade, pró-atividade [...]" (E11)

Tal análise é confirmada ao verificarmos porcentagem da frequência das palavras "formulário", remetendo à existência do Registro de Atitudes, como instrumento mais significativo, senão o único e "preceptor", ressaltando sua figura de avaliador, bem como, o alto valor de quiquadrado $\left(x^{2}\right)$, demonstrando a forte relação dessas palavras com a definição desta classe.

Outros $16,7 \%$, denominada DESCONHECIMENTO, foram segmentos de textos que enfatizaram a não existência de métodos ou instrumentos avaliativos no programa de Residência como ilustram as falas:

"Não conheço e acredito que até agora não exista" (E3)

"Não sei se para os R2 já foram apresentados, mas para mim ainda não." (E5)

Nesta classe, as palavras com maior frequência e qui-quadrado foram "não" e "existir", confirmando sua apresentação no dendograma e seu significado.

O segundo sub-corpus, apresentou 2 partições. Em uma delas, a classe mais significativa, com $25 \%$ dos segmentos de texto, foi definida como AVALIAÇÃO PRÁTICA, está relacionada aos métodos e instrumentos que são utilizados na avaliação em campo de prática:

"Na prática, foi apresentado o método avaliativo" (E9)

"Avaliação na prática ao terminar a prática em um determinado setor" (E10)

"Nós temos um documento que avalia as competências na prática" (E12)

"Eu tenho muita dúvida em relação a eles (métodos), porque nossa avaliação foi mais feita pelos preceptores" (E4) 
O alto índice de frequência de repetição e qui-quadrado das palavras "avaliativo", "prático", "processo", "apresentar" e "método", reforçam a origem da classe determinada.

As demais classes estão relacionadas aos métodos avaliativos e seus instrumentos, durante as aulas teóricas. A classe denominada MÉTODOS INDIVIDUALIZADOS, relata a particularidade de cada professor em suas aulas, com $22,2 \%$ dos segmentos de texto do corpus e está exemplificada nas falas seguintes:

\footnotetext{
"Nas aulas teóricas, os professores antes de começar as aulas, eles mostram como a gente vai ser avaliado" (E6) "Nas disciplinas teóricas a avaliação foi produção de trabalho" (E1)

"Nas aulas que nós temos, os professores esclarecem, e nem todos fazem isso..." (E2)
}

Nesta classe, as palavras com maior frequência e qui-quadrado foram "como", "avaliação", "aula", "método", "professor" e "claro", justificando a classe gerada pela análise.

Em 19,4\%, de falas estavam relacionadas a um método de AVALIAÇÃO COLETIVA, sendo assim denominada. Trata-se de um método que, segundo eles, acaba sendo insuficiente e/ou superficial:

"Durante as aulas tem muita discussão, faz muito debate, a gente conversa..." (E6)

"É muito complicado avaliar criatividade, modo de conversação porque cada um tem seu jeito" (E7)

Neste estudo, a avaliação coletiva foi enfatizada por alguns residentes, não havendo tarefas individuais com fins avaliativos.

Santos (2010), em sua investigação com a Residência Multiprofissional em Saúde da Família identificou alguns dos instrumentos supracitados na classe "Avaliação Coletiva", como participação em debates e seminários. Além disso, os instrumentos eram convenientes à rotina dos residentes, havendo uma diversificação, com diários de campo, apresentação de 
casos de família, além de fichamento dos textos base, utilizados nos tutoriais (aulas teóricas).

Resultados semelhantes à presente pesquisa, também foram encontrados nos estudos de Silveira (2011), que ouviu residentes sobre a experiência do Contrato Didático. No que concerne à estruturação das atividades teóricas, a maioria dos residentes entrevistados em sua pesquisa, julgava ter clareza quanto às regras (incluindo processo avaliativo) nas atividades teóricas, assemelhando-se a partição Avaliação Teórica, gerada neste estudo.

O dendograma abaixo (Gráfico 2) foi gerado a partir da segunda pergunta do roteiro de entrevista - "Qual o sentido e o significado do processo avaliativo no programa de residência?"

GRÁFICO 2 - Gráfico do conteúdo analisado pelo corpus "sentido e significado de um processo avaliativo na residência multiprofissional".

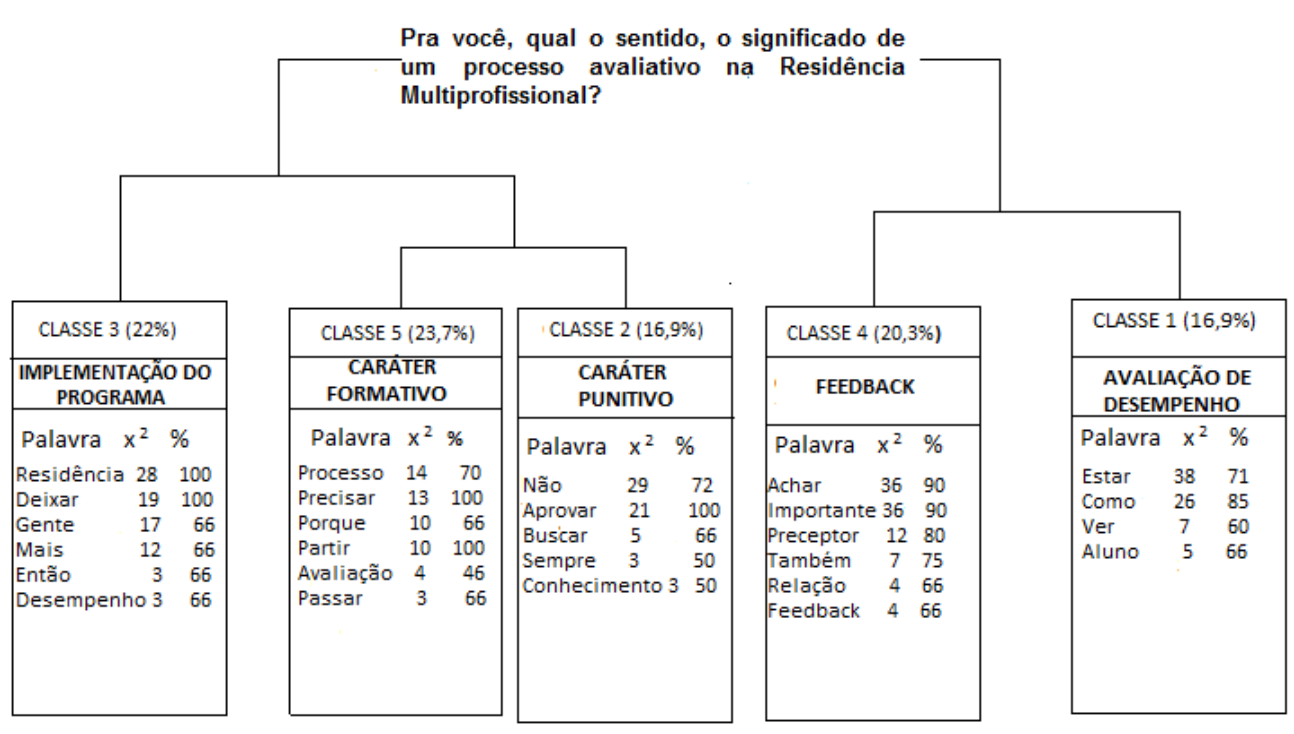

Fonte: Dados do autor (2017)

A classe denominada AVALIAÇÃO DE DESEMPENHO, equivale a $15,9 \%$, dos segmentos de textos analisados e está ilustrada pelas falas a seguir: 
"Primeiro para ver como é que está o andamento do processo de ensino-aprendizagem em relação ao desempenho do aluno" (E2)

"De estar percebendo como está o aprimoramento quanto ao residente" (E7)

As palavras "estar", "ver", "como" e "aluno", foram as mais frequentemente encontradas nos segmentos analisados, bem como, apresentaram maior qui-quadrado, reforçando a relação destas palavras com a definição da classe feita pelo Iramuteq e denominada pelo pesquisador.

$\mathrm{Na}$ classe FEEDBACK, observamos na fala dos residentes, a preocupação com o feedback desta avaliação de desempenho, sendo este o significado mais pertinente do processo avaliativo:

"Saber como está o seu feedback" (E4)

"Saber onde você está errando, onde você está acertando" (E2)

"Primeiramente, acho que é importante porque nos dá um feedback em relação ao nosso trabalho" (E3)

Essa foi uma classe bem expressiva na fala dos entrevistados, representando $20,3 \%$ dos segmentos de textos associados. O gráfico mostra as palavras mais frequentes e seu qui-quadrado, que foram: "achar", "importante", "preceptor", "também", "relação" e "feedback".

A classe denominada CARÁTER FORMATIVO, resultou de $23,7 \%$ dos segmentos de textos encontrados nas falas dos residentes. No gráfico, as palavras "processo", "precisar", "porque", "partir", "avaliação" e "passar", foram as mais frequentes e que apresentaram maior qui-quadrado e, consequentemente, relação com a classe. Esta, levou em consideração o caráter formativo do sistema avaliativo, sendo utilizado para 0 aperfeiçoamento do mesmo e para melhoramento de sua condução:

"Para poder conseguir melhorar cada vez mais esse processo de ensino-aprendizagem" (E2) "Porque ela (avaliação) vai demonstrar falhas..." (E5) 
"Pra mim, precisa ter essa avaliação, uma avaliação contínua" (E8)

A classe CARÁTER PUNITIVO equivale a $16,9 \%$ dos segmentos de texto, e revela a visão dos residentes acerca da vinculação do sistema de avaliação à possibilidade de reprovação do residente, impedindo-o de adquirir seu título:

"A avaliação faz com que o residente esteja sempre buscando conhecimento para se manter na disciplina, se manter aprovado" (E1)

"Se você está atingindo certos pontos, que são critérios para você passar" (E4)

Esta classe apresentou as palavras "não", "aprovar", "buscar", "sempre" e "conhecimento", com maior porcentagem de frequência e quiquadrado, confirmando a categorização desta classe.

Com relação a esta temática mencionada no discurso dos residentes, Santos (2010) afirma que o processo de avaliação perpassa por punição ao residente, quando não atingir os critérios estabelecidos pela avaliação, podendo, inclusive reprovar este residente.

Contrapondo esta ideia, Sousa et al (2008) entende que não cabe em um modelo de formação em serviço, o ato de aprovar ou reprovar determinado aluno, sendo inclusive, um fato gerador de impasse ético, já que ao residente é prevista uma bolsa em dinheiro, para que conclua sua especialidade em 24 meses, não prevendo prorrogação deste benefício.

Sendo assim, cabe a reflexão sobre o objetivo de submeter o residente a um processo avaliativo, que apresenta um caráter punitivo, qual o sentido e em que isso contribuiria para o processo de ensino-aprendizagem e para formação deste profissional. Também nos remete a analisar se as diretrizes que regem a formação em serviço, através das Residências Multiprofissionais, deveriam mencionar a possibilidade de algum residente não desenvolver ao longo de sua formação, o perfil profissional pretendido pelas DCN's, e quais seriam as intervenções realizadas para corrigir esta realidade. 
A última classe gerada com $22 \%$ dos segmentos de texto relacionados, denominada "IMPLEMENTAÇÃO DO PROGRAMA", é a classe correspondente à percepção dos residentes sobre o processo avaliativo ser inerente ao programa de residência, fazendo parte obrigatoriamente de sua estrutura, enquanto um processo de ensino-aprendizagem e aperfeiçoamento profissional.

"A partir do momento que nós sabemos que vamos passar por um processo avaliativo, a gente se compromete mais". (E 3)

"Precisa ter essa avaliação". (E8)

"É pra alimentar o sistema da residência". (E10)

Nos discursos, também foi revelada a compreensão de que trata-se de um programa de pós-graduação, implantado recentemente, que necessita de aperfeiçoamento e evolução, exigindo ainda mais comprometimento dos atores envolvidos.

"Essa residência que é uma residência muito nova, ela tem muito a melhorar..." (E2)

"A residência precisa de dados...saber se está sendo proveitoso o programa". (R3)

Nesta classe, as palavras de maior frequência e qui-quadradro, sendo responsáveis pela conclusão na sua definição foram: "residência", "deixar", "gente", "mais", "então" e "desempenho". Diante do exposto, ficou explícita a percepção da importância de um processo avaliativo como estratégia de ensino-aprendizagem na Residência.

Ficou explícita a percepção da importância de um processo avaliativo, como estratégia de ensino-aprendizagem na Residência. Holanda (2015) reforça a ideia de que a avaliação é um exercício de reflexão, no qual o ser humano repensa seus atos e analisa-os, não só com o mundo, como com outros seres, sendo assim possível a tomada de decisões com via a transformação da realidade, seja através da identificação de problemas, como também, do reconhecimento de qualidades e potencialidades. 
O dendograma que segue (Gráfico 3) refere-se à terceira pergunta voltada para os residentes - Quais os quesitos importantes para serem levados em consideração durante um processo avaliativo?

GRÁFICO 3 - Gráfico do conteúdo analisado pelo corpus "aspectos importantes em um processo avaliativo na residência multiprofissional"

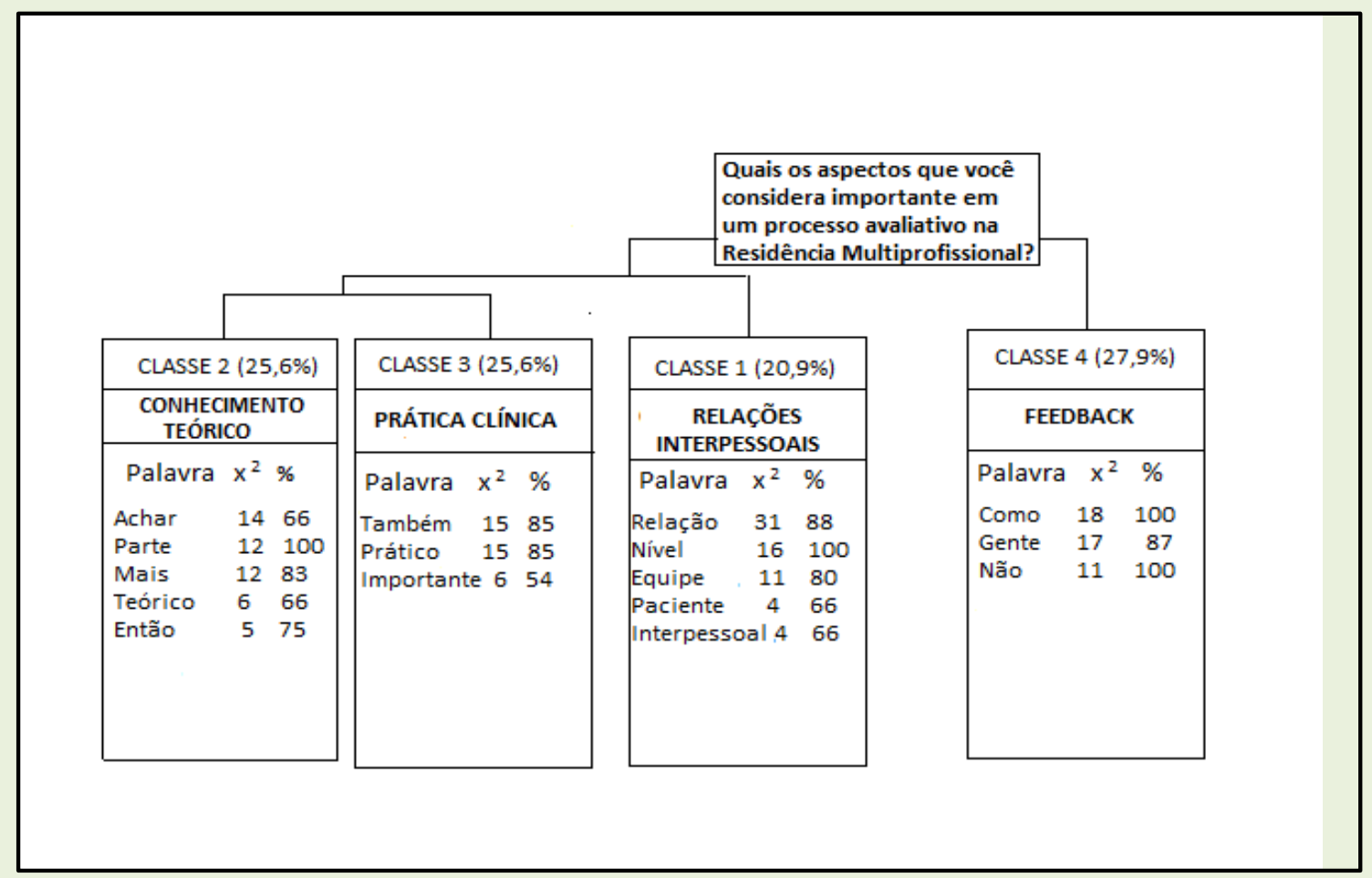

Fonte: Dados do autor (2017)

A classe denominada FEEDBACK, equivalente à $27,9 \%$ de ocorrência nos segmentos de textos, revela a associação que os residentes fazem dos quesitos avaliativos e o feedback do seu desempenho de uma maneira geral, sendo de considerável importância que tais quesitos sejam adequados à realidade deles e capazes de desenhar sua evolução. As falas seguintes justificam a percepção gerada:

"Perceber no nosso método como a gente atende...como a gente nos direciona... como a gente avalia..." (E3)

"Ter a devolutiva dos preceptores pra saber como está sendo a minha atuação" (E12) 
Nesta classe, as palavras mais representativas foram: "como", "não" e "gente", reforçando a ideia de avaliação pessoal e seu feedback.

O feedback, é uma oportunidade gerada pela avaliação formativa para preceptor, tutor, residente e coordenação, afim de propiciar crescimentos de todos os envolvidos (BADUY et al, 2006). De fato, é um quesito de extrema importância, e que inquieta os residentes entrevistados, já que revelam, no decorrer dos discursos, que não existe esse momento de compartilhamento sobre o seu desempenho, na perspectiva de seus avaliadores, oportunizando a eles melhorarem ou modificarem sua prática.

Na classe denominada RELAÇÕES INTERPESSOAIS, estão as relações humanas do residente para com outros sujeitos, sejam eles da equipe de serviço ou próprio paciente, totalizando $20,9 \%$ de ocorrência, conforme ilustra as falas seguintes:

"As relações interpessoais que o residente estabelece dentro da equipe" (E2)

"Trato com o usuário" (E9)

"Relação humana, vínculo profissional-paciente" (E7)

As palavras de maior ocorrência foram: "relação", "nível", "equipe", "paciente" e "interpessoal", reforçam a identificação desta classe. Ratificando a definição desta classe, o gráfico apresenta as palavras de maior ocorrência e sua relação: "relação", "nível", "equipe", "paciente" e "interpessoal". Demonstra a importância dada pelos entrevistados à relação não somente com os demais profissionais do serviço, permitindo um compartilhamento de saberes, e práticas, potencializando o cuidado com o paciente. Lopes (2014), afirma que tal relação leva a uma reflexão do profissional sobre a sua conduta, a partir do conhecimento e materialidade das práticas dos demais profissionais.

Essa realidade nos revela a tentativa de ruptura com o conceito de saúde fragmentada, que ainda persiste em vários espaços de saúde pública, embora esteja desalinhada com as propostas das DCN's e do SUS.de uma formação mais generalista dos profissionais de saúde. 
Já a relação com o paciente, permite ao profissional mais que registros técnicos, uma proximidade com a história deste paciente, sendo esta, um elemento facilitador do planejamento terapêutico aplicado à situação do usuário.

As classes denominadas PRÁTICA CLÍNICA $(25,6 \%)$, e CONHECIMENTO TEÓRICO $(25,6 \%)$, obtiveram a mesma porcentagem de ocorrência, revelando a importância atribuída a esta relação pelos residentes.

"Se ele tá conseguindo associar com a prática" (E2)

"Na prática, acho que tem alguns aspectos importantes a serem avaliados" (E3)

"Na parte teórica, acho que a gente sempre deve manter nosso conhecimento atualizado" (E3)

"A parte teórica é muito importante" (E4)

"Conhecimento específico nas aulas teóricas" (E5)

Para a classe Conhecimento Teórico, o gráfico apresenta as palavras "achar", "parte", "mais", "teórico" e "então", como as de maior correlação com a definição categorial. Já para a classe Prática Clínica, as palavras mais ocorrentes e com maior qui-quadrado foram: "também", "prático" e "importante".

A complexidade do ato avaliativo foi abordada por Vieira e Souza (2009), que ressaltam que um estudante da área da saúde, não deve apenas se limitar a adquirir conhecimentos cognitivos fundamentais, mas, deve também, ter domínio de uma série de habilidades com complexidade variável, que nem sempre são fáceis de avaliar.

Espera-se que ao final do processo de ensino-aprendizagem, o residente descubra a importância do trabalho coletivo, correlacione teoria e prática, sendo estas habilidades alcançadas a partir de relações pedagógicas, ou seja, relações que almejem a aprendizagem prática do aluno (REGO, 1994)

Santos (2010) ouviu dos residentes, quesitos semelhantes que deveriam ser observados no processo avaliativo. Dentre eles, foram destacados: pontualidade, relações estabelecidas entre residentes e equipes das 
Unidades e o desempenho quanto ao processo de trabalho de acordo com as competências almejadas.

A última pergunta questionava - Quais as dificuldades encontradas por você durante o processo avaliativo? A análise do corpus resultou no gráfico abaixo.

GRÁFICO 4 - Gráfico do conteúdo analisado pelo corpus "dificuldades encontradas no processo avaliativo da residência multiprofissional"

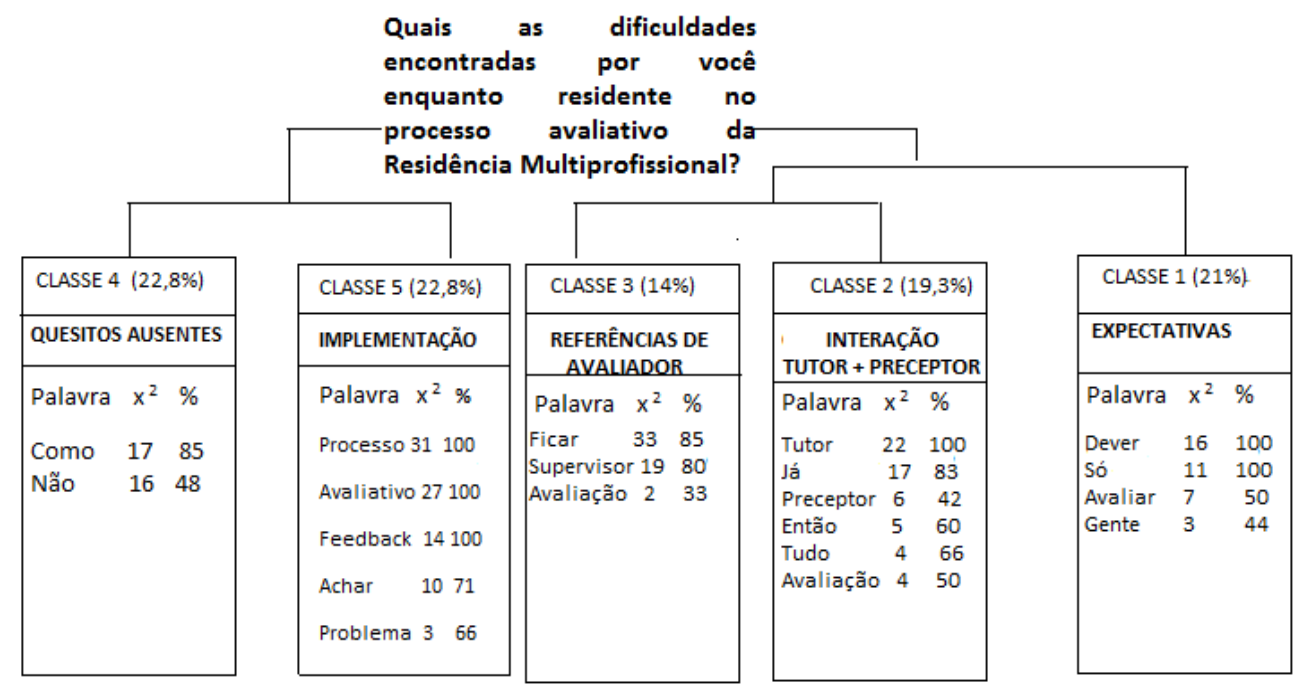

Fonte: Dados do autor (2017)

Na classe EXPECTATIVAS, observou-se na fala dos residentes a ânsia por uma avaliação diferente daquela que vivenciam, sugerindo novos métodos e formas de avaliar seu desempenho:

"Um avalia de uma forma, outro de outra forma" (E2)

"Deveria ter um momento só pra avaliar, pra gente ouvir o avaliador" (E8)

"Eles (supervisor) que deveriam nos acompanhar no campo de prática" (E8)

"Autoavaliação é perigoso" (E7)

Nesta classe, as palavras com maior porcentagem de frequência e com maior relação à definição da classe foram: "dever", "só", "avaliar" e 
"gente". Observamos nas falas dos residentes, muitas angústias e insatisfações, por não serem contemplados com um processo avaliativo mais explícito e justo, segundo seus conceitos. De fato, diversos estudos revelam o distanciamento do modelo desejado para formação desses profissionais, do que ainda vivenciamos, gerando expectativas de uma formação mais problematizadora, emancipadora e criativa, impossibilitando o avanço da ciência, do conhecimento, da educação e da liberdade (ROMÃO, 2008).

A classe INTEGRAÇÃO TUTOR-PRECEPTOR resultou da ocorrência em 19,3\% dos segmentos de textos analisado. Esta classe deixou explícita a falta de integração entre a atividade da tutoria, que se dá no âmbito das aulas teóricas, e da preceptoria, que está delimitada ao ensino em serviço. Residentes declaram que esse fato acaba dificultando o aprendizado, afastando realidades, que na verdade são indissociáveis. Palavras como "tutor", "já", "preceptor", "então", "tudo" e "avaliação", justificam a definição da classe e sua categorização. As falas que seguem ilustram a classe:

"Se a gente conseguisse pôr tutores que sejam daquela área da residência..." (E4)

"Então, às vezes, infelizmente acaba entrando nesse conflito" (E4)

"Falta de comunicação entre tutor e preceptor" (E12)

"Ainda não vi avaliação do preceptor e do tutor" (E9)

Com relação à REFERÊNCIA DE UM AVALIADOR, $14 \%$ do conteúdo das falas estavam no sentido da dúvida que os residentes têm com a figura do supervisor, que segundo eles, assina a avaliação, porém não os acompanha no campo de prática. Sendo assim, sugerem que o profissional que está no serviço, acompanhando suas atuações, seja também responsável por avaliá-lo, assinando sua ficha avaliativa:

"Dizem que os preceptores são os supervisores, mas, eles acabam não sendo quem fica com a gente" (E8)

"Mas quem fica com a gente não é o supervisor". (E6) 
Alguns atribuem essa falha à falta de tempo que o preceptor teria em realizar este ato mais burocrático, delegando sua função de avaliador para outro profissional que não teria a mesma vivência prática com o residente.

"Falta de tempo para o preceptor avaliar. A avaliação fica a desejar" (E8)

"Entregamos (Registros e Atitudes) para o preceptor, mas, quem vai avaliar é o supervisor" (E6)

No levantamento das palavras com maior ocorrência e seus índices de relação com a classe estão: "ficar", "supervisor" e "avaliação".

Esta problemática sobre funções distintas dos educadores em um programa de Residência foi abordada por Sousa et. al (2008), esclarecendo que, preceptores e tutores são profissionais que compartilham de uma mesma ação: a educativa; de um mesmo foco: o processo de trabalho do residente; de um mesmo objetivo: facilitador do processo de construção das competências pelo residente.

A diferença entre estes elementos seria o objeto do processo de trabalho. Para preceptores, cabe a construção de conhecimentos, habilidades e atitudes específicas à categoria profissional que está inserido. Já o tutor tem seu objeto mais difuso, sendo seu limite exatamente definido pelos componentes do processo de trabalho onde atua o preceptor, dessa forma, fica clara a complementaridade das ações desses educadores.

Steinbach (2015), em sua pesquisa com preceptoria na Residência Multiprofissional, identificou a dinâmica denominada Ação Integrada Multidisciplinar, que consistia em momentos de reflexão e planejamento realizados entre residentes, tutores e preceptores, colocando desta forma, a figura do tutor lado a lado com o preceptor.

Quanto à figura do supervisor, Botti e Rego (2008), em uma extensa pesquisa sobre a temática, elucidaram que, em vários artigos científicos, sua função está atrelada a uma espécie de modelo a ser seguido pelo residente, ser conselheiro e colega, além de saber demonstrar habilidades, ser instrutor, facilitador e, também, saber avaliar. Em suma, o supervisor tem como principais atribuições observar alguém na realização de determinada 
atividade, zelar por essa pessoa e ter a certeza de que ela exerce sua atividade.

O CNRMS orienta que preceptores e tutores da área de concentração trabalhem em conjunto, elaborando escalas de plantões e de férias, desenvolvam o plano de atividades teórico-práticas e acompanhem sua execução (BRASIL, 2012).

O subcorpus, relacionado ao conteúdo sobre o Sistema Avaliativo, gerou duas partições definidas como as classes da Implementação e Quesitos Ausentes.

$\mathrm{Na}$ classe com 22,8\% dos segmentos de texto, denominada IMPLEMENTAÇÃO, foram relatadas dificuldades associadas à implementação do processo avaliativo, bem como, suas consequências ao programa de Residência. Corroboram para esta definição as palavras: "processo", "avaliativo", "feedback", "achar" e "problema", citadas mais frequentemente e com maior associação à classe.

Fatores como ausência de feedback aos envolvidos e elaboração do processo avaliativo, foram relatados também nesta classe, conforme falas abaixo:

"O problema, são as pessoas que são responsáveis pela elaboração do processo" (E2)

"Estão tentando começar a montar esse processo avaliativo" (E2)

"Não existe feedback, por parte dessa relação do preceptor para com os residentes ou da coordenação para com os residentes" (E2)

Também houve entrevistado que julgou o processo avaliativo inexistente:

"Não encontrei nenhuma dificuldade porque até então a residência não tem nenhum processo avaliativo" (E3)

O processo de construção de um Programa de Residência, já foi exposto em estudos de Baduy et al. (2006), caracterizado por espaços de conversas entre todas as categorias profissionais propostas para o curso, 
universidade e serviço público de saúde. Tais espaços permitiram momentos de reflexão com relação às práticas educativas e assistenciais através da participação ativa dos envolvidos, definindo uma sistematização das estratégias de aprendizagem, inclusive a avaliação.

A classe QUESITOS AUSENTES (22,8\%), revelou a insatisfação dos residentes pela ausência ou insuficiência de alguns quesitos avaliativos que eles julgam importantes para a solidificação do sistema Avaliativo, conforme ilustram as falas:

"Não tem participação de nenhum pedagogo" (E2)

"Não vi nenhum tipo de papel (ficha avaliativa)" (E2)

"Direcionamento para a traumatologia e ortopedia" (E4)

"Os preceptores não sabem como funciona a residência, eles veem a gente como uma ajuda" (E8)

"A professora usou um instrumento que não teria como fazer por conta da nossa sobrecarga de atividades" (E12)

Ratificam a definição desta classe, as palavras "como" e "não", mais frequentemente citadas e com maior associação a esta.

Lopes (2014), em seus estudos com residentes e preceptores, concluiu que, na visão dos participantes o processo avaliativo, ainda não cumpre com o compromisso ético-pedagógico de investigação do desenvolvimento da aprendizagem do educando, revelando limites e possibilidade, assim como, não assumiu a função de propiciadora à reflexão da prática educativa ao residente.

Também foi identificado pela autora, relatos sobre o distanciamento entre preceptor e residente, dificultando assim o acompanhamento das atividades do residente, a identificação de dificuldades e até mesmo de possíveis divergências, inviabilizando a oportunidade de lidar com a questão interpessoal.

Em consonância com as diretrizes da CNRMS (BRASIL, 2012), preceptores e tutores, devem, em conjunto, proceder à formalização do processo avaliativo do residente, com periodicidade máxima bimestral, o que não foi revelado pelos entrevistados na presente pesquisa. 
Toda esta precarização, levantada pelos residentes do processo ensino-aprendizagem, gera frustração e desânimo, caracterizando o programa de Residência com um fim apenas utilitário para Universidade e Serviços de Saúde, como destaca Lopes (2014), a academia cumprindo com a função de garantir vagas para práticas curriculares, e os serviços aproveitando a mão de obra dos residentes oferecidas nos campos de prática.

\section{CONCLUSÃO}

A presente pesquisa levantou um tema fundamental no processo de ensino-aprendizagem que necessita ser explorado nos Programas de Residência Multiprofissionais, ainda em processo de consolidação, em diversas regiões do país: avaliação.

A realidade relatada pelos entrevistados é diferente da preconizada pelas instituições idealizadoras dos Programas de Residência Multiprofissional e das DCN's, que anunciam um processo avaliativo dialógico, propiciando ao residente a revisão de sua prática educativa em qualquer fase do processo de ensino-aprendizagem.

Com relação aos métodos e instrumentos avaliativos utilizados na Residência, notou-se nas falas dos entrevistados duas vertentes equilibradas. A primeira revela os conhecedores dos instrumentos e métodos que devem ser utilizados, embora, não necessariamente, sintam-se seguros em manuseálos. Em alguns casos, até se ouviu que nunca haveria feito uso do instrumento fornecido pela coordenação, o Registro de Atitudes.

Residentes demonstraram vários questionamentos sobre o instrumento e o manuseio por parte de seus avaliadores, alguns inclusive sentindo-se prejudicados com o processo de avaliação vigente. Foram destaque, as queixas com relação ao tempo que o preceptor dispõe para acompanhar seus residentes na prática, o que inviabilizaria uma avaliação fidedigna à realidade. Também foi destacado o fato da subjetividade dos quesitos a serem avaliados no Registro de Atitudes, que traria insegurança ao residente na tentativa de suprir as expectativas diferenciadas de cada avaliador. 
Outros residentes foram enfáticos ao dizer que não havia processo avaliativo ou que nunca haviam sido avaliados.

O feedback avaliativo foi um item bastante explorado na fala dos residentes. Eles atribuíram uma fundamental importância ao feedback do processo avaliativo, como forma de corrigir erros e potencializar habilidades, sugerindo inclusive, que houvesse um momento específico dentro de cada setor de prática em que pudessem discutir as suas avaliações em todas suas nuances. Entende-se que preceptores não possuem segurança para exercer seus papéis de avaliadores, resultando nesta ausência de retorno aos residentes sobre seu desempenho.

De fato, estes resultados apresentaram muitas aproximações com estudos semelhantes sobre o mesmo tema. Tomando por fato a importância em se aprimorar o processo avaliativo no ensino em serviço, sugere-se que mais programas sejam investigados, traçando assim uma realidade mais abrangente $e$ identificando as dificuldades que podem e devem ser contornadas em prol de uma formação de qualidade.

Faz-se necessário, estudos complementares que abordem tal temática, e que possam experimentar novas formas e instrumentos de avaliação de aprendizagem, a exemplo de outros estudos, na busca de aperfeiçoamento e consolidação de um processo avaliativo que fortaleça a formação dos profissionais de saúde conforme a necessidade e diretrizes do SUS.

\section{REFERÊNCIAS}

ABIB, L. T. "Caminhando contra o vento...": a história das Residências Integradas Multiprofissionais em Saúde. Porto Alegre, 2012. Disponível em: <http://www.lume.ufrgs.br/bitstream/handle/10183/70214/000875764.pdf?seq vence $=1>$. Acesso em: 18 Out. 2015.

ALONSO, M., GIL PEREZ, G. e TORREGROSSA, M. Los examenes de física en la ensenanza por transmisíon y en la ensenanza por investigacion. Ensenanza de las ciencias, vol. 10, n. 2, pp. 127-138, 1992

BADUY, R. S.; LIMA, J. V. C.; CARVALHO, B. G. Movimentos, encontros e desencontros da produção da residência multiprofissional em Saúde Família. 
Residência Multiprofissional em Saúde: experiências, avanços e desafios. Ministério da Saúde. Pp. 230-249. Brasília, DF, 2006.

BOTTI, S.; REGO, S. Preceptor, supervisor, tutor e mentor: quais são seus papéis? Revista Brasileira de Educação Medica. v. 32. n. 3, p. 363-373, 2008.

BRASIL. Ministério da Saúde. Secretaria de Gestão do Trabalho e da Educação na Saúde. Departamento de gestão da educação na Saúde. Residência multiprofissional em saúde: experiências, avanços e desafios. Ministério da Saúde, Secretaria de Gestão do Trabalho e da Educação na Saúde, Departamento de Gestão da Educação em Saúde. Brasília: Ministério da Saúde, 2006.

BRASIL. Ministério da Educação. Relatório de Atividades da Comissão Nacional de Residência Multiprofissional em Saúde - CNRMS Exercício 2007/2009 Brasília-DF. Disponível em:

http://portal.mec.gov.br/index.php?option=com_docman\&view=download \&alias $=1594$-relatorio-atividades-cnrms\&ltemid=30192. Acesso em: 25 de Jul de 2017

BRASIL. Secretaria de Educação Superior. Comissão Nacional de Residência Multiprofissional em Saúde (CNRMS). Resolução n² de 13 de abril de 2012. Dispõe sobre as diretrizes gerais para os programas de residência multiprofissional e em áreas da saúde. Brasília, DF. Disponível em: http://www.normaslegais.com.br/legislacao/resolucao-cnrms-2-2012.htm

DIAS, A. R. N.; FREITAS, J. J. S. A percepção e conhecimentos dos profissionais de saúde de uma unidade de ensino-assistência em relação à atividade de preceptoria. Belém, 2014. Dissertação (Mestrado em Ensino em Saúde na Amazônia) - Universidade do Estado do Pará. Belém, 2014

HOLANDA, C. M. Proposta de Auto-Avaliação da Residência Multprofissional em Saúde em Hospitais Universitários do Ceará. 2015. Disponível em:

<https://sucupira.capes.gov.br/sucupira/public/consultas/coleta/trabalhoCo nclusao/viewTrabalhoConclusao.jsf?popup=true\&id_trabalho=2491804> Acesso em: 01 de Julho de 2017.

LOPES, E. F. S. A formação em serviço no Programa de Residência Integrada Multiprofissional em Saúde do Hospital de Clínicas de Porto Alegre (PRIMS/HCPA). 366 ff. Tese (doutorado). Universidade Federal do Rio Grande do Sul. Faculdade de Educação. Programa de Pós-Graduação em Educação. Porto Alegre, 2014.

REGO, S. A prática na formação médica: os estágios extracurriculares em questão [dissertação]. Rio de Janeiro: Instituto de Medicina Social, Universidade Estadual do Rio de Janeiro, 1994.

RICER, R. E. Defining preceptor, mentor and role model. FamMed, 30 (5): 328. USA, 1998. 
ROMÃO, J. E. Avaliação Dialógica: desafios e perspectivas. São Paulo, Cortez, 2008.

SANTOS, F. A. Análise Crítica dos Projetos Político Pedagógicos de dois Programas de Residência Multiprofissional em Saúde da Família. Dissertação (mestrado). Ciencias na área de Saúde Pública. Escola Nacional de Saúde Pública. Rio de Janeiro, 2010.

SILVA, L. C. O processo ensino-aprendizagem na residência multiprofissional em saúde: preceptores. $3^{\circ}$ Encontro Internacional de Política Social. $10^{\circ}$ Encontro Nacional de Política Nacional. 2015

SILVEIRA, L. H. A. Avaliação do conhecimento dos residentes de um programa de residência multiprofissional em saúde, referente ao "contrato didático". Dissertação (mestrado). Universidade Federal do Rio Grande do Sul. Faculdade de Medicina, Programa de Pós-Graduação em Saúde da Criança e do Adolescente. Porto Alegre, 2011

SOUSA et al. A Residência Multiprofissional em Saúde da Família de SobralCeará. SANARE, Sobral, v. 7, n. 2, p. 23-30. jul/dez. 2008

SOUZA, F. L. As estruturas essenciais de avaliação de programas de residência multiprofissional em saúde da família no Ceará: uma proposta de autoavaliação a partir dos casos de Sobral e Fortaleza. 2012. $129 \mathrm{f}$.

Dissertação (Mestrado Acadêmico em Saúde da Família) - Universidade Federal do Ceará - Faculdade de Medicina de Sobral, Sobral, 2012.

STEINBACH, M. A preceptoria na residência multiprofissional: saberes do ensino e do serviço. Dissertação (mestrado). Universidade Federal de Santa Catarina. Centro de Ciências da Saúde. Programa de Pós-Graduação em Odontologia. Florianópolis-SC, 2015.

TURATO, E. R. Métodos qualitativos e quantitativos na área da saúde: definições, diferenças e seus objetos de pesquisa. Saúde Pública. São Paulo V. 39, n. 3, pp. 507-514, abr. 2005.

VIEIRA, V. M. O.; SOUZA, C. P. Contribuição do Portfólio para Avaliação do Aluno Universitário. Revista Estudos em Avaliação. Educacional, São Paulo-SP, v. 20, n.43, 235-255, 2009.

Recebido: 19 de março de 2018

Aprovado: 16 de agosto de 2018 